\title{
Using Technology Acceptance Model to assess teachers' attitude towards use of technology as teaching tool : A SEM Approach
}

\author{
Indu Nair \\ Ph.D. Scholar, \\ Dr. MGR Educational and \\ Research Institute, Chennai , India
}

\author{
V. Mukunda Das \\ Director, CIMP-Patna , \\ Patna, India
}

\begin{abstract}
To supplement the traditional teaching, in the last few years a steady growth of ICT applications and IT courseware development has taken place in India. Only a few studies have evaluated acceptance of such new technologies among teachers. An attempt is made to understand the attitude of mathematics teachers towards IT as an instructional tool in the State Schools of Kerala (India), using the Technology Acceptance Model (TAM) framework. Results suggested that TAM being a robust model can be effectively used in this context too and a good fit for the proposed model for the data was found. The sample consisted of only the high school mathematics teachers, who seem to agree about the usefulness of computers in teaching mathematics, but were found not very conversant in using these as teaching tools. This factor leads to the finding of the study showing Teachers' Perceived Ease of Use having significant impact on their perception about Usefulness and Attitude towards use of IT in teaching.
\end{abstract}

\section{Keywords :}

Attitude towards use, SEM , AMOS, TAM, ICT use in education, Perceived ease of use , Perceived Usefulness

\section{INTRODUCTION}

Various studies conducted across the globe indicate many advantages of using IT tools in teaching and learning process , but in India the conviction to use technology in teaching by teachers seems to be an area not studied much. In the State of Kerala (in India), where this study is conducted, seeing the potential of new teaching and learning practices which can promote modern thinking and learning skills among students, a lot of initiatives are taken up by the State Govt. thru a project called IT@School. The state govt. schools in Kerala have had world's largest simultaneous deployment of Open Source Software based Information and Communication Technology educational initiatives claims the project website. Tremendous efforts are put in for the infrastructure upgradation of schools under the ICT scheme by way of setting up computer labs , providing Broadband internet connectivity , Content development for teachers and students, creating a School wiki for collaborative content development and providing a educational channel called ViCTERS targeting students, teachers and parents. There is no research required to see a whole hearted support and usage by student community for all such initiatives but there seems to be a gap between these benefits and the actual use by teachers. In this context, to further investigate and predict the teacher's acceptance of technology as a teaching tool, the researchers have attempted to use the most widely applied theoretical model in Information Systems field, the Technology Acceptance Model (TAM). The study aims at evaluating the attitude of teachers towards use of technology as a teaching tool to enhance teaching and learning process.

\section{TECHNOLOGY ACCEPTANCE MODEL- A FRAMEWORK USED}

Technology Acceptance Model (TAM) been used by the researchers as it the most widely researched theoretical model used to explain adoption of new systems and other information technologies. TAM, based on the Theory of Reasoned Action [Fishbein and Ajzen, 1980], is a simple model of IT adoption that claims that the Overall IT acceptance or utilization is based on users' beliefs like (a) system's perceived usefulness (PU) and (b) systems' perceived ease-of-use (PEOU), which are the major impact factors for their (c) attitude towards use (ATT) and also (d) Behavioural Intentions to use (BI).

Thus usually TAM studies can have three hypotheses associated with these fundamental constructs - First, PEOU is expected to influence variables Attitude to use the system and PU. PEOU and PU taken as independent variables can both together influence Attitudes toward use chosen as Dependent Variable. [1]

Though a long literature review and discussion of TAM research is not required here, the data gathering and measurement tool descriptions are relevant. The Figure 1, given below illustrates the basic research model showing the causal linkages in TAM .

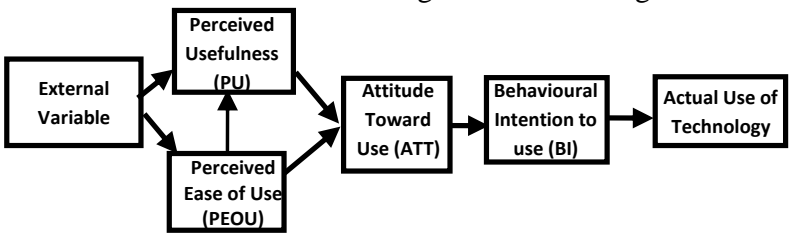

Fig 1: Technology Acceptance Model (TAM)* [2] 


\section{METHODOLOGY}

\subsection{Research Methodology}

TAM [Davis, 1989] [2] is taken as model to assess perception of teachers about using technology as teaching tool . As in most of the technology acceptance research, in this research too a theory based approach is taken and hypotheses are put forward and tested. Also taking a clue from the previous researchers a data is collected using a questionnaire with yes/no answers and Likert scales . Remaining with the framework the findings are then mapped to the teachers' attitude towards technology use in teaching . [3]

As in the most of technology acceptance studies here too the Structural Equation Modeling (SEM) is used for validating instruments and testing significance between the constructs. A complete analysis using SEM can be achieved either thru a Covariance Analysis [used in LISREL, EQS and AMOS ] or Partial Least Squares [ used in PLS and PLS-Graph ]. These two types of SEM differ not only in the objectives of their analysis but on the statistical hypotheses they are based on and the statistical fit that they produce also . The objective of the covariance-based SEM is to (1) show that the null hypothesis ( the assumed research model with all its paths) - is insignificant and the paths specified in the model which is being analysed, are reasonable for the given sample data (2) establish overall model fit indices thru different measures showing various types of fit. Since the Covariance based SEM methods indicate the overall fit of the hypothesized model with the observed covariance matrix ; for the present confirmatory research study in this article, Covariance based SEM is used. [4]

\subsection{Research Hypotheses}

Based on the three factors of TAM , in the proposed Teacher's Attitude towards Technology Use Model (TATUM) on a target sample of mathematics teachers, the Intentions to use technology in teaching is defined in terms of teachers' perceptions about technology and their attitude towards technology use. The following hypotheses were considered to assess the attitude towards using and actual intention to use computers in teaching and learning process among the mathematics teachers in the State Schools.

$\mathrm{H}_{1}$ : Perceived ease of use has a significant effect on attitude towards using computers. [PEOU->ATT]

$\mathrm{H}_{2}$ : Perceived usefulness has a significant effect on attitude towards using computers.[PU->ATT]

$\mathrm{H}_{3}$ : Perceived ease of use has a significant effect on Perceived usefulness. [PEOU->PU]

Using SEM, these paths were modeled in one analysis (Fig 2). [4]

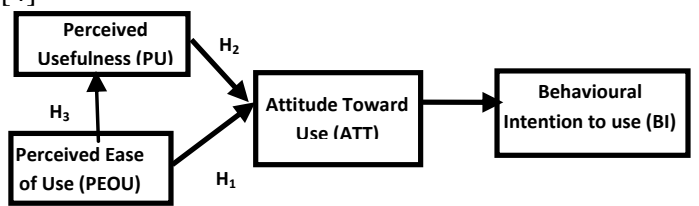

Fig:2 Teacher's Attitude to Use Technology Model (TTUM) In most of the previous studies of TAM the variance in the self reported use was measured and not the system use. Thus it can be assumed that obviously this is not a precise measure as the self reported use can be only a relative indicator. Even in cases where inclusion of additional variables is seen, TAM could hardly explain $40 \%$ of the variance in use. [5]

\subsection{Research Participants}

A sample of 195 Kerala State Govt. High School Teachers teaching Mathematics, drawn from various cities across the State, was selected and administered with a questionnaire survey. All teachers chosen in the sample had undergone at least one workshop on IT enabled education and have had hands-on training on Software used for teaching Mathematics (e.g. DrGeo, Geogebra etc.) along with general use of Computers.

\subsection{Research Instruments \& Data Collection}

The study has used a survey questionnaire, designed on the theoretical references of previous works in this area mainly, Davis (1989) [1], Williams(2006) [6], and Napaporn(2007)[7]. Likert's five point scale of extremity was employed to indicate the degree of acceptance as 1 indicates strongly agree unto 5 for strongly disagree.

A convenient sampling approach is adopted to verify the hypotheses. A paper-and-pencil questionnaire survey was administered among school teachers teaching Mathematics in Kerala State Government High Schools across the State of Kerala (a state in south India). The questionnaire was distributed by hand to teachers while they were going thru their annual teacher's training workshop on mathematics teaching methods, as preparation for the new academic year starting in June 2011. The participants were requested to fill in the questionnaire, during their lunch break. In addition to the demographic information part, the participating teachers were asked to indicate their perception and level of agreement with a number of measures that have been acknowledged by previous research studies as having an influence on the effectiveness of technology in teaching and learning. [1], [6], [7]

The measures that were considered in this study included teachers' perception regarding (a) Usefulness of Computers, (b) Ease of Computer Use, and (c) Attitude towards use of Computers. Data collected was checked for errors, and then was fed into the SEM software package called AMOS 18 and statistical package SPSS 17.

\section{DATA ANALYSIS \\ 4.1 Sample Demographics}

The questionnaire was administered to 220 mathematics teachers. Incomplete responses were discarded, leaving 195 fully completed questionnaires, i.e., $89 \%$ of those issued, for data analysis. The sample consisted with $80 \%$ teachers belonging to the age group 35 and above and the rest between 25-35 years. The $86 \%$ teachers in sample have computers at home. More demographics are detailed in Table 1. 
Table 1 : Demographic characteristics

\begin{tabular}{|l|}
\hline Academic Qualification \\
\hline Graduate - $69 \%$ \\
Post Graduate $-31 \%$ \\
\hline Experience in Using Computers \\
\hline 2 years or less - $30 \%$ \\
3-5 years $-30 \%$ \\
More than 5 years - $40 \%$ \\
\hline Work Experience \\
\hline up to 5 years $-6.7 \%$ \\
6-10 years $-17.4 \%$ \\
$11-20$ years $-41.0 \%$ \\
\hline
\end{tabular}

The proposed Teacher's Attitude towards Technology Use Model (TATUM) was put to test thru the Covariance based SEM package AMOS to generate statistics mainly to analyse the model at three levels : 1) at individual item and construct level, 2) the overall fit for model level, and 3) individual path analysis level.

\section{RESULTS}

\subsection{Instrument Construction and Validation}

Reliability Analysis in SPSS 17 , done to test the Construct Validity and reliability, had the following output :

Reliability - While using Likert-type scales it is essential to calculate and report the "Scale reliability coefficient" , Cronbach's Alpha $(\alpha)$, for internal consistency, reliability for the scales or subscales being used. The analysis is done on the summated scales and not for individual items. The Cronbach's alpha $(\alpha)$ can have value ranging from 0 to 1 and the internal reliability of the items in the scale is said to be the maximum when it is closer to 1 . An $(\alpha)$ value of 0.70 and above is considered to be the criterion for demonstrating internal consistency of the scale (Nunnally, 1978) . [8]

Thus theoretically, higher the Cronbach's Alpha, the better, i.e. the correlation between the observed value and the true value should be as high as possible. Study measured all the 23 items of the questionnaire and the reliability testing of these variables revealed Cronbach's alpha of 0.786 as shown in Table 2, confirming the reliabilities of these scales within the commonly accepted range exceeding 0.70 .

Table 2: Reliability Statistics

\begin{tabular}{|c|c|c|}
\hline $\begin{array}{c}\text { Cronbach's } \\
\text { Alpha }(\alpha)\end{array}$ & $\begin{array}{c}\text { Cronbach's Alpha Based on } \\
\text { Standardized Items }\end{array}$ & $\begin{array}{c}\text { No. of } \\
\text { Items }\end{array}$ \\
\hline 0.786 & 0.821 & 23 \\
\hline
\end{tabular}

Table 3: Item- Total Statistics - Cronbach's Alpha if Item Deleted

\begin{tabular}{|cccc|}
\hline PU1 & PU2 & PU3 & PU4 \\
0.773 & 0.784 & 0.783 & 0.77 \\
\hline PU5 & PU6 & PU7 & PU8 \\
0.778 & 0.775 & 0.778 & 0.771 \\
\hline PEOU1 & PEOU2 & PEOU3 & PEOU4 \\
0.774 & 0.774 & 0.787 & 0.768 \\
\hline
\end{tabular}

\begin{tabular}{|c|c|c|c|}
\hline PEOU5 & PEOU6 & PEOU7 & PEOU8 \\
0.773 & $\mathbf{0 . 8 0 1}$ & 0.782 & 0.765 \\
\hline ATT1 & ATT2 & ATT3 & ATT4 \\
0.797 & 0.767 & $\mathbf{0 . 8 1 6}$ & 0.772 \\
\hline ATT5 & ATT6 & ATT7 \\
0.779 & 0.763 & 0.772 & \\
\hline
\end{tabular}

On a closer look at the Table 3 with Item-total statistics value of $\alpha$, if item deleted, it was observed that there are two items PEOU6 $=0.801$ and ATT3 $=0.816$ with values more than total $\alpha$, indicating that if these two items are removed the $\alpha$ value can be increased to 0.801 and 0.816 respectively. In Questionnaire PEOU6 is response to the question " Is learning software a time consuming process ?" and ATT3 is from the question on teacher's feelings towards computer discussions off class hours, and if these two items are removed from the analysis, the Cronbach's Alpha $(\alpha)$ becomes 0.829 and the number of items reduced to 21. [9]

Table 4: Revised Reliability Statistics

\begin{tabular}{|c|c|c|}
\hline $\begin{array}{c}\text { Cronbach's } \\
\text { Alpha }(\alpha)\end{array}$ & $\begin{array}{c}\text { Cronbach's Alpha Based on } \\
\text { Standardized Items }\end{array}$ & $\begin{array}{c}\text { No. of } \\
\text { Items }\end{array}$ \\
\hline 0.829 & 0.848 & 21 \\
\hline
\end{tabular}

Thus the revised $(\alpha)$ value of 0.829 shows good internal consistency and construct validity.

\subsection{Confirmatory Factor Analysis}

AMOS 18 software was used to estimate the structural parameters of the proposed Teacher's Attitude towards Technology Use Model (TATUM), based on Confirmatory Factor Analysis (CFA). AMOS gives fit statistics such as the Chi-square $\left(\chi^{2}\right), \mathrm{DF}$ its degrees of freedom, $\mathrm{P}$ the probability value , CFI , the Comparative Fit Index, TLI and RMSEA the Tucker-Lewis Index, and the Root Mean Square Error of Approximation respectively. Standardized Root Mean Residual (SRMR) is another statistics given. Table 5 displays the model fit, parameters, and corresponding statistics for the TATUM. Chi-square for the model was given as 496.10 with 186 degrees of freedom.

Table 5. Model fit statistics for the proposed model

\begin{tabular}{|c|c|c|c|c|}
\hline$\chi^{\mathbf{2}}$ & DF & P & Normed $\chi^{\mathbf{2}}$ & GFI \\
\hline 496.10 & 186 & .000 & 2.667 & .794 \\
\hline AGFI & NFI & TLI & CFI & SRMR \\
\hline .744 & .653 & .713 & .745 & .072 \\
\hline
\end{tabular}


Since the probability value of the chi-square test is smaller than the acceptance level of $>.05$, the null hypothesis should be rejected, that the model doesn't fit the data. To further investigate the overall fitness of the Model, other values like , the Comparative Fit Index (CFI) and the Tucker-Lewis Index (TLI) were looked at, which compare the absolute fit of the specified model to the absolute fit of the model. The larger the values of these descriptive statistics, the greater the inconsistency between the overall fit of the model. [10], [11] As recommended by $\mathrm{Hu}$ and Bentler (1999) [12], RMSEA values below .06 and .95 or higher values of TLI are the other descriptive measures of fit. The RMSEA value of .093 and the Tucker-Lewis Index TLI value of .713 for this model indicate that the model does not fit well according to the descriptive measures of fit. [13],[14]

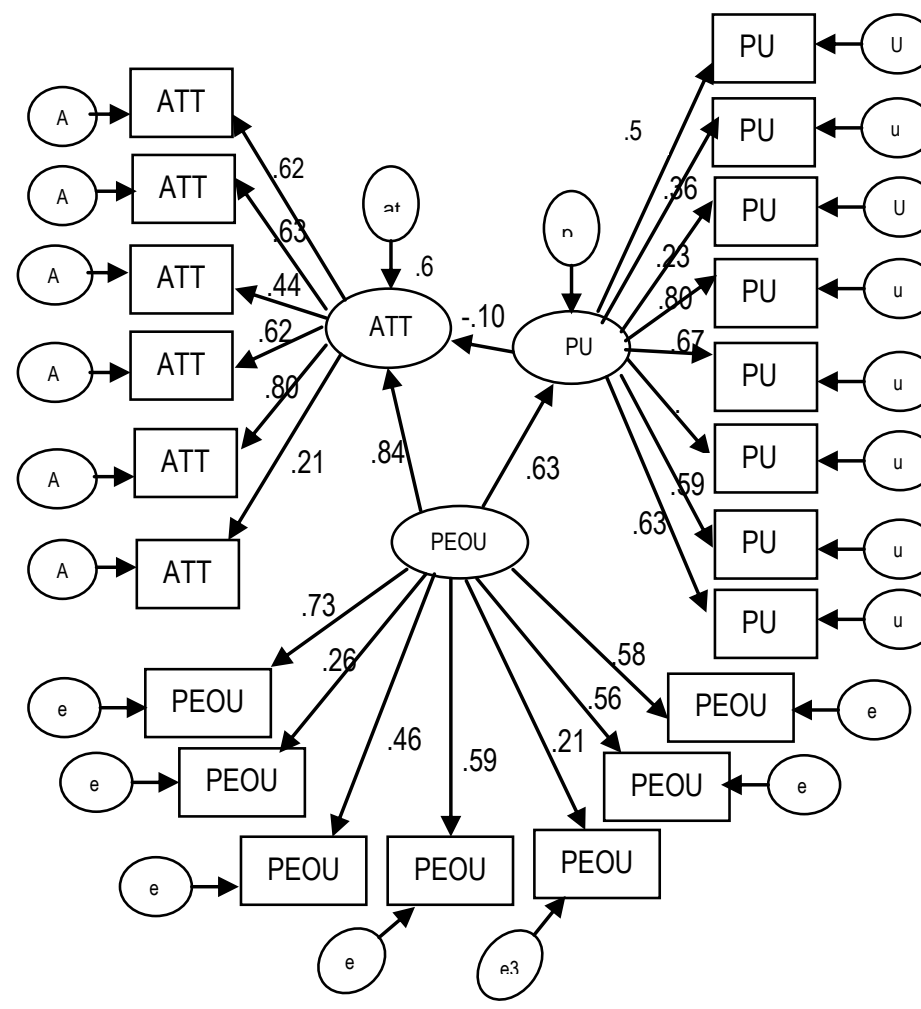

Figure 2: The parameter estimates of general Structural Model ( TATUM )

\subsection{Modifying the Model to obtain superior goodness of fit}

To get a better model fit, model modification is required in this current study. AMOS feature for modification indices to get the expected reduction in the chi-square for each possible path that can be added to the model was used. All possible variances were estimated, so that there were no unmodeled variances that could be estimated in the modified or revised model. All the possible regression weights and co-variances were incorporated into a re-specified model that resulted in substantial changes in the model fit chi-square test statistic as shown in Table 6. [16]
Table 6. Modified fit statistics for the proposed model

\begin{tabular}{|c|c|c|c|c|c|}
\hline$\chi^{2}$ & DF & P & Normed $\chi^{2}$ & GFI & RMSEA \\
\hline 234.58 & 144 & .000 & 1.629 & .899 & .057 \\
\hline AGFI & NFI & TLI & CFI & RMR & IFI \\
\hline .839 & .836 & .892 & .926 & .053 & .930 \\
\hline
\end{tabular}

According to Kline (1998), a value of a relative chi-square index of 3 or less suggests adequate model fit. Here, a relative chisquare fit index (Normed $\chi 2$ ), calculated by dividing the chisquare value by the degrees of freedom, given as 1.629 (234.58/144), shows that the model fits well . The Incremental Fit Index (IFI) and Standardized Root Mean Square Residual (RMR) were given as 0.93 and 0.053 , respectively, to suggest a good fit to the data. Other fit indices were also within acceptable limits. These include AGFI, RMSEA, NFI, and CFI, which were given as $0.839,0.057,0.836$, and 0.926 , respectively.

A Comprehensive Fit Index (CFI) of $0.926(>0.90)$ for the construct has been said to imply that there is a strong evidence of unidimensionality (Ahire,1978). Unidimensionality indicates the items of the Factor/Construct measure one common latent variable. While analyzing the goodness of fit for the model even after modifying the same, showed the favorable statistics in the RMSEA fit statistics with the obtained value of .057 , just below the desired cutoff of .06 , and chi-square value of 239.58 with 144 degrees of freedom and normed chi-square of 1.629 , well below 3 but for TLI result of .892 , which is below the required threshold of .95 and above . [17]

\subsection{Significance tests of individual parameters}

Table 7 shown below, gives the Estimate, the Standard Error (S.E.) and Critical Ratio (C.R.), which is nothing but the estimate divided by S.E., also referred as t-value, followed by Probability Value (P) associated with the null hypothesis, in various columns. As seen here the regression weights in this model are significantly more than 0 , beyond the .01 level and so also are the t-values, all found to be significant for all item loadings to the latent constructs and for every path except for the PU->ATT, which seems a bit contrary to the TAM assumption. [17]

All path coefficients were significant ( $\mathrm{p}<0.05)$ except one. Thus we can reject the null hypothesis and say that Perceived ease of Use (PEOU) has positively affected teachers' attitude towards computer use and PEOU has a significant effect on Perceived Usefulness as well. But for the sample being considered, PU seems to have insignificant effect or negative effect on the Attitude towards using. Therefore, the generated hypotheses $\mathrm{H}_{1}$ and $\mathrm{H}_{3}$ were supported but $\mathrm{H}_{2}$ was not supported by the sample. Table 7 . Regression Weights: (Final Structural model)

\begin{tabular}{|l|rrrrr|}
\hline $\begin{array}{c}\text { Hypothesized } \\
\text { path }\end{array}$ & Estimate & S.E. & $\begin{array}{l}\text { C.R. } \\
(\mathbf{t})\end{array}$ & P & Remarks \\
\hline PEOU ->ATT $\left(\mathrm{H}_{1}\right)$ & 1.400 & .546 & 2.563 & .010 & Supported \\
PU-> ATT $\left(\mathrm{H}_{2}\right)$ & -.051 & .211 & -.243 & .808 & $\begin{array}{c}\text { Not } \\
\text { Pupported }\end{array}$ \\
PEOU->PU $\left(\mathrm{H}_{3}\right)$ & .682 & .356 & 1.918 & .054 & Supported \\
\hline
\end{tabular}

The model could express $61 \%$ of the variance associated with Attitude towards use of computers in teaching $\left(\mathrm{R}^{2}=.61\right)$. 


\section{CONCLUSIONS}

In the study thru item analysis, the reliability and unidimensionality of scale construct were established showing aptness of the questions included in the scale. The study finds TAM as a useful model to help the researcher understand the attitude of teachers to use technology in teaching in this context as the model has a food fit for the collected data.

Though more than $70 \%$ of the mathematics teachers are very conversant with using computers otherwise and are aware of the all the software provided by Govt. for teaching mathematics, the findings indicate that teachers perception about ease of use of these tools dominate their attitude towards use in teaching. Teachers' perception about usefulness is also significantly effected by the perception about ease of use. Thus it can be said that the teachers' would find the IT tools more useful and will have a positive attitude towards integration of technology in teaching if thru adequate training they are made more proficient in using such tools. The lack of support for $\mathrm{H}_{3}$ can be explained by the very fact that as the tools are already given to the teachers and usage is mandatory in this case, thus the results are not surprising. [19] , [20]

The findings also indicate a need to extend the research model in order to find the external factors / variables as the model proposed with the existing TAM variables could explain only $61 \%$ of variance. The future work can be 1 . in the future works, researchers need to examine new variables that could be used to extend the TAM model with the inclusion of some constructs related to the infrastructure, technology and subject domain related constructs which can have a direct or indirect (but significant) impact on teachers' attitudes and intention for using computer technology. 2. An examination of acceptance using TAM on different teaching tools and contexts to explore its validity 3. Study how TAM can be used in predicting actual usage of technology.

As in all empirical studies this research also has limitations such as -1 . the sample is limited to mathematics teachers who are given training in using software as the results may vary in case of other subject teachers and hence the results can not be generalized ,2. the used constructs based on original TAM and donot consider any IT implementation related constructs which can be playing major factors in teachers' perceptions and attitude about IT tools in teaching. 3. Though the study gives indications that TAM can be used to assess the attitude and can be useful for a large population of teachers, the generalizations of the findings are limited to high school mathematics teachers only.

So as a concluding remark it can be said that the study was successful to show the causal relationships among the TAM constructs (PU, PEOU, and ATT) and had evidences in support of applicability of TAM in explaining attitude of mathematics teachers in Kerala. The results obtained from this study would complement efforts taken by the Govt. and provide useful insight into the process of implementation of ICT based instructional technology and development of e-content for Mathematics subject as such in the Kerala State Syllabus Schools.

\section{REFERENCES}

[1] M. Waheed and F. Ahmed Jam, "Teacher s Intention to Accept Online Education : Extended TAM Model," Interdisciplinary Journal of Contemporary Research In Business, September 2010, vol. 2, no. 5, pp. 330-345.

[2] Davis, F. D., Bagozzi, R. P., Warshaw, P. R. , User Acceptance of Computer Technology: A Comparison of Two Theoretical Models, Management Science, 35, 1989, 982-1003."

[3] Gilbert, J., \& Kelly, R. (2005). Frontiers and frontlines: metaphors describing lecturers' attitudes to ICT adoption. Educational Technology \& Society, 8 (3), 110-121.

[4] David Gefen., Detmar W. Straub. \& Marie-Claude Boudreau (2000). Structural Equation Modeling Techniques and Regression : Guidelines for Research Practice . Communications of AIS, Volume4, Article 7.

[5] Paul Legris, John Ingham, Pierre Collerette (2003), Why do people use information technology? A critical review of the technology acceptance model, Information \& Management , 40, 191-204

[6] Williams, Carol Koger (2006), An investigation of attitudes of K-12 teachers toward computer technology use in schools in a rural Mississippi district , Ph.D. Thesis, Mississippi State University, USA,

[7] Kripanont Napaporn (2007), Examining a Technology Acceptance Model of Internet Usage by Academics within Thai Business Schools, Ph.D. Thesis, Victoria University, Melbourne, Australia

[8] M. Masrom and U. Teknologi (2007), "Technology Acceptance Model and E-learning," Paper presented in 12th International Conference on Education , Sultan Hassanal Bolkiah Institute of Education , Universiti Brunei Darussalam, pp. 1-10.

[9] Keller, C., Hrastinski, S. \& Carlsson, S. A. (2007). Students' Acceptance of E-learning. Environments: A Comparative Study in Sweden and Lithuania, pp. 395-406

[10] T. Teo, C. B. Lee, and C. S. Chai (2007), "Understanding pre-service teachers' computer attitudes: applying and extending the technology acceptance model," Journal of Computer Assisted Learning, vol. 24, no. 2, pp. 128-143.

[11] N. O. Ndubisi and F. T. Labuan (2008), "Factors influencing e-learning adoption intention : Examining the determinant structure of the decomposed theory of planned behaviour constructs," Journal of Cyber Therapy and Rehabiliation, Vol 1 ,No. 2, pp. 252-262.

[12] Hu, L.T. \& Bentler, P.M. (1998). Fit Indices in Covariance Structure Modeling: Sensitivity to Underparameterized Model Misspecification. Psychological Methods, 3(4), 424453.

[13] Abdalla, I. (2007). Evaluating effectiveness of eblackboard system using TAM framework: A structural analysis approach. AACE Journal, 15(3), 279-287.

[14] Sumak B., Hericko M., Pusnik M. and Polancic Gregor (2011), Factors Affecting Acceptance and Use of Moodle: An Empirical Study Based on TAM, Informatica 35 , 91100.

[15] Halawi, L., McCarthy R. . ( 2008) . Measuring students perceptions of Blackboard using the Technology Acceptance Model : A PLS Approach. Issues in Information Systems, Vol IX, No.2.

[16] Kline, R. B. (1998). Principles and Practice of Structural Equation Modeling. New York: The Guilford Press. 
[17] Structured Equation Modeling Using AMOS : An Introduction , http://www.utexas.edu/cc/stat/tutorials lamos/index.html , last accessed on 2/28/2010 1:15:40 PM

[18] Park, S. Y. (2009). An Analysis of the Technology Acceptance Model in Understanding University Students' Behavioral Intention to Use e-Learning. Educational Technology \& Society, 12 (3), 150-162.

[19] Chuttur M.Y. (2009). "Overview of the Technology Acceptance Model: Origins, Developments and Future
Directions" Indiana University, USA . Sprouts: Working Papers on Information Systems, 9(37). http://sprouts.aisnet.org/9-37

[20] Bulent Cavas , Pınar Cavas , Bahar Karaoglan \& Tarik Kisla (2009), A study of science teachers' attitude toward Information and Communication Technologies in Education , The Turkish Online Journal of Educational Technology - TOJET ISSN: 1303-6521 volume 8 Issue 2 Article 2 